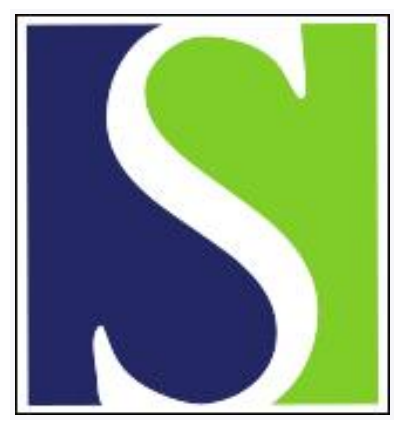

Scand J Work Environ Health 2006;32(6):413-419

https://doi.org/10.5271/sjweh.1047

Issue date: 31 Dec 2006

Work-related stress and health-risks, mechanisms and countermeasures

by Härmä M, Kompier MAJ, Vahtera J

Affiliation: Centre of Expertise on Human Factors at Work, Finnish Institute of Occupational Health, Helsinki, Finland. mikko.harma@ttl.fi

Refers to the following texts of the Journal: 2006;32(6):421-430

2006;32(6):473-481 2006;32(6):431-442 2006;32(6):443-462

2006;32(6):502-514 2003;29(3):171-188 2006;32(6):463-472

2006;32(6):482-492 2006;32(6):493-501 2006;32(6):515-527

The following articles refer to this text: $2007 ; 33(1): 1-3$;

2008;34(1):48-54; 2010;36(2):96-108; 2018;44(4):394-402;

2020;46(1):1-4

Key terms: countermeasure; editorial; health; mechanism; risk; work-related stress

This article in PubMed: www.ncbi.nlm.nih.gov/pubmed/17173198

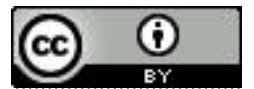




\section{Work-related stress and health-risks, mechanisms and countermeasures}

Profound changes occurring in the economic, political, technological, and social landscape have transformed the world. And because the world has changed, also the world of work has changed (1). The most striking development is the changing nature of work itself-from physical to mental. Another major development is that the significance of time and time-related activities in work has increased. Furthermore, due to the systematic intensification of work, the psychosocial workload has increased. Accordingly, today, for many employees, work poses primarily mental and emotional demands. At the same time, job and work security have decreased. Moreover, work and family life have become blended. It is now generally recognized that, as a result of these developments, work-related stress has become a major public health problem with serious consequences for the individual, companies, and society.

Although the concept of stress is very popular, both in the academic world and in the everyday world, it has been difficult to agree on the exact scientific definition. According to Kristensen et al (2) stress is an individual, psychophysiological, and subjective state, characterized by a combination of high arousal and displeasure. In this issue of the Scandinavian Journal of Work, Environment \& Health, in line with this definition, Siegrist \& Rödel (3) specify stress as a latent construct that indicates a state of elevated activation of the autonomic nervous system with coordinated manifestations at the affective, cognitive, and behavioral levels. To study the health aspects of stressful work characteristics, general theoretical work-stress models, like those for job strain (4) and effort-reward imbalance (5), have been developed and tested. Also in this issue of the Scandinavian Journal of Work Environment \& Health, several papers $(3,6,7,8)$ have used these models and more-recent conceptualizations, such as organizational injustice, to explore the association between work stress and health. Work stress thus refers to the aspects of work design, organization, and management, and their social and organizational contexts, that have the potential to cause harm to employee health. This paradigm, in addition to the conventional physicochemical approach, forms an essential part of contemporary occupational health research (6).

The aim of this special issue of the Scandinavian Journal of Work, Environment \& Health is to clarify the knowledge and understanding of the risks and mechanisms of work-related stress and to review current challenges and some approaches for the prevention of work-related stress.

\section{Risks}

In the first contribution to this issue, Kompier (1) concentrates on modern worklife. He aims at identifying major changes in and around work organizations, their effects upon job characteristics and the health and well-being of today's employees, and research challenges in this area.

He emphasizes the following four developments: increased internationalization and competition, increased utilization of information and communication technology, the changing configuration of the workforce, and flexibility and new organizational practices. He concludes that new systems of work organization have become more prevalent, but do no not represent a radical change across the whole economy, and that their effects (good or bad) depend on their design, implementation, and management.

The second paper, a systematic review and meta-analysis on work stress in the etiology of coronary heart disease (CHD) by Kivimäki and his colleagues (6), found 11 independent studies examining the job-strain model, four studies examining the model for effort-reward imbalance, and two studies examining the organizational injustice model. The results showed a $43 \%$ excess risk for CHD among employees with high job strain. For effort-reward imbalance and organizational injustice, the excess risk 
was $58 \%$ and $62 \%$, respectively. Kivimäki and his co-workers concluded that observational data suggest an average of $50 \%$ excess risk for CHD for employees with work stress. Another meta-analysis, based on 12 prospective studies, suggests that work stress is also a risk factor for the development of common mental disorders (7). Other research has shown that organizational changes, such as downsizing and mergers, are associated with an increased risk of death from cardiovascular disease, as well as with heightened morbidity and disability retirement among the remaining employees (9-11). The excess risk is partially attributable to an elevated level of work stress after such changes (12). Thus the evidence available indicates that the contribution of work stress to the disease burden on employees is substantial.

The changes in worklife have also increased the flexibility and diversity of workhours. A review on the association between workhours and health in this issue (8) suggests that night work and shift work are related to a wide range of health effects, the evidence for the risk of cardiovascular morbidity being the strongest. A positive, albeit weak, relation has been found between long workhours and ill health (13). Long workhours can affect health by impairing the employee's possibilities for sufficient recovery, both mentally and physiologically. Long hours also pose health risks if exposure to adverse work conditions is prolonged and if health-related behavior is affected. The possibilities of workers' influencing their workhours may enable them to adjust their workhours to the demands at work and also to the demands of their private lives. Therefore, perceived control over worktimes may reduce health problems that derive from work stress and also from stress due to conflicting demands from paid and domestic work. Indeed, high employee worktime control has been shown to predict good subjective health and less sickness absence and to be associated with reduced stress-related absenteeism $(14,15)$. Interestingly, the associations between long domestic, commuting, and total workhours and subsequent morbidity have been found to be attenuated in combination with high control over workhours (16). This is an important finding, as it suggests that providing employees with control over worktimes may promote both employee health and a successful combination of full-time paid work and domestic responsibilities.

However, there are also several methodological limitations in the existing evidence. As acknowledged by Kivimäki and his co-workers (6), additional studies with more sophisticated assessment strategies are needed to develop a more complete picture of the role of work stress in the evolution of an illness. Also in this issue, Taris \& Kompier (17) give a demonstration of the problems faced by a researcher using longitudinal data to examine causality in a nonexperimental context. They evaluated two approaches using a large data set from a three-wave study. They show that extreme groups analysis, a commonly applied strategy to maximize the power of statistical tests, may magnify bias due to regression to the mean. Instead, they suggest that researchers should maximize the chances of observing significant substantive change by taking advantage of naturally occurring experiments. One example of such a natural experiment is organizational downsizing, a proxy measure of increase in job strain and effort-reward imbalance among those who keep their jobs (12). In a recent study, downsizing was associated with an increased risk of cardiovascular mortality among these employees, the greatest excess risk occurring in the years immediately after personnel reductions (9). This time-dependent effect pattern supports a causal, rather than a confounded, association between downsizing and cardiovascular mortality.

\section{Mechanisms}

The search for mechanisms through which work stress elicits harmful effects on health constitutes a major challenge in occupational research. Work stress is associated with unhealthy living habits like smoking, physical inactivity and unhealthy diet, the activation of the hypothalamo-pituitary-adrenocortical (HPA) system, insufficient recovery and sleep, an activated autonomic system, impaired inflammatory and immune responses, and early atherosclerosis. In this issue, Siegrist \& Rödel (3) review 46 tudies published since 1989 on the associations between psychosocial stress at work and health risk behavior. 
The review suggests that at least some part of the burden of disease attributable to a health-adverse psychosocial work environment is explained by an unhealthy lifestyle, in particular in relation to alcohol consumption, overweight, and cigarette smoking. In the meta-analysis of Kivimäki et al (6), the association between work stress and CHD was also substantially lower after adjustment for covariates, such as socioeconomic position, body mass index, blood pressure, cholesterol concentration, smoking, and sedentary lifestyle. It is thus obvious that work stress increases the probability of a co-manifestation of several risk factors in the individual, thus predisposing them to chronic disease development.

Geurts \& Sonnentag (18) present a conceptual approach to recovery as an explanatory mechanism underlying the relationship between acute physiological stress reactions and chronic health impairment. It is argued that the two conditions may suppress the recovery process by sustaining physiological activation, prolonged exposure to work demands (working long hours) and cognitive stress-related processes (such as rumination of work-related issues). Both conditions would prolong physiological activation and result in "allostatic load", related to the load on the autonomic nervous system, the HPA axis, and metabolic and immune systems. The theory is well justified by earlier theories on effort, recovery, and sustained activation and evidence from experimental and on-site field studies.

The contribution of Härmä (8) extends the discussion on the association of long workhours and psychosocial work characteristics, recovery, and health by also taking into consideration the other characteristics of workhours. This paper concludes that long workhours are related to high work demands and often with greater possibilities to influence the work situation. One of the most consistent pathways from extensive workhours to health indeed passes through decreased recovery and insufficient sleep, but this pathway may concern only those with high psychological work demands. Shift work, on the other hand, is related to lower job control and socioeconomic class and other health risks in the work environment, as well as to living habits. However, the disruption of the circadian rhythms and insufficient sleep are still the probable triggers for independent physiological, metabolic, and endocrinological changes leading to obesity and the other health effects related to night and shift work. The review of Härmä (8) suggests that insufficient or poor sleep, in relation to insufficient recovery, could actually be a common pathway from long workhours, shift work, and work stress to cardiovascular illness. Work demands and control, according to the job-strain model, have a strong cross-sectional relationship with insomnia, sleep deprivation, and daytime fatigue independent of workhours and lifestyle factors like physical activity, smoking, and alcohol consumption (19, 20). Short sleep and insomnia have also proved to be good and even independent predictors of obesity, cardiovascular health, and type II diabetes $(21,22,23,24)$.

The review of Åkerstedt (25) demonstrates that stress is closely related to impaired sleep. It seems that stress involves increased psychological and physiological activation in response to demands (26) and that an activated HPA system seems incompatible with normal sleep. In particular, the anticipation of high demands or effort the next day seems important. Shortened or disturbed sleep causes additional increases in levels of traditional stress markers like cortisol, heart rate, metabolic rate, activation of the autonomic nervous system, glucose tolerance, and immunologic functions and may thus exacerbate the effects of stress. It is thus likely that the resulting sleep impairment due to work stress will cause additional increments in the HPA system and thus promote a vicious circle of stress and insomnia. Psychologically, both rumination and the anticipation of stress seem to be key factors in insomnia, supporting the assumption that the cognitive stress-related processes are indeed important with respect to recovery from acute stress (18).

\section{Countermeasures}

Many authors of articles in this issue of the Scandinavian Journal of Work, Environment \& Health have paid attention to measures that may improve the psychosocial work environment in order to reduce 
work-related stress and illness. Some do so in more detail $(8,27)$, whereas Siegrist \& Rödel (3) discuss the perspective of a person-focused health-promoting lifestyle.

In his contribution, Norbert Semmer (27) distinguishes between three categories of intervention (ie, changing task characteristics, changing work conditions, and changing social conditions at work. Each approach is described briefly and illustrated with empirical examples. These examples, in turn, illustrate important issues, which are then discussed in more detail. Among these issues are levels of intervention (organizational and individual), inconsistencies in outcomes, compensatory effects and side effects, methodological aspects, and, finally, the focus of change. One of the conclusions of Semmer is that, preferably, intervention programs should combine work-directed and person-directed measures.

The paper by Mikko Härmä (8) presents an overview of measures that aim at improving recovery through well-chosen work and rest schedules. Härmä concludes that the most-promising measures are (i) regulation of (extreme) overtime and excessive workhours, (ii) an increase in individual worktime control, and (iii) the introduction of sleep-promoting principles in shift rotation. As for the latter, rapidly forward-rotating shifts are to be preferred, as they tend to minimize the infringement on human circadian systems.

Siegrist \& Rödel (3), who investigated the nature of the associations between an unfavorable psychosocial work environment and health risk behavior (cigarette smoking, alcohol consumption, and overweight), conclude that their "findings support measures of a health-promoting lifestyle as part of worksite intervention programs [p 479]". However, these authors emphasize that such health promotion efforts should be embedded in a broader program directed at structural measures of task redesign, organizational justice, and career and promotion prospects, including job security.

\section{General conclusions and directions for future research}

Over the last 50 years, our understanding of the interplay between the psychosocial work environment and health has significantly increased. Nowadays, work-related stress constitutes both an acknowledged research and policy domain. Through this special issue, we have aimed at contributing to this development by presenting a series of high-quality reviews that strive for accumulated knowledge and by paying attention to methodological issues. Our purpose was to concentrate on psychological, physiological, and behavioral mechanisms that underlie the work and health relationship, and on prevention and intervention. On the basis of these contributions, we believe that several conclusions can be drawn.

First, there is no doubt that certain (profiles of) work characteristics are major risk factors for stress and ill health. Among these factors are very high psychological demands, too little variety in work, insufficient possibilities for control, job insecurity, insufficient quality of functional and social contact at work, an unrewarding work structure, and organizational injustice.

Second, most interestingly, stress is clearly a question of (dis)balance. The predominant job-stress theories all share the notion of (disturbed) equilibrium in the organization of work (demands versus control, effort versus rewards, effort versus recovery possibilities, and unfair treatment versus justice as a fundamental value in social interaction). In other words, basically, there is not much wrong with working very hard. However, high quantitative and qualitative job demands tend to become a problem in cases of long duration, high frequency, too little return on investments (rewards), and insufficient possibilities for recovery. Control, including worktime control, appears to be the key word here-having or lacking the possibilities to decide about activities for one's self is crucial.

Third, we learn more and more with respect to the various pathways between exposure to certain work characteristics and health outcomes. There is now increasing evidence for the existence of two central mechanisms, a psychophysiological mechanism and a behavioral lifestyle mechanism.

Fourth, it is clear that interventions are initiated to reduce occupational stress. Such interventions may address the worker, in order to increase his or her coping capacity; they may address the 
organization of work, improving the balance between demands and control, efforts and rewards (costs and benefits), effort and recovery, workload and coping capacity, and decision-making procedures; and they may address the social policy in organizations by reducing organizational injustice (eg, by improving decision-making procedures and the treatment of employees with fairness, politeness, and consideration by supervisors). Intervention studies are challenging because they may provide tests of theories, and because they may have great social relevance.

Against the background of these general conclusions, we would now like to present four directions for future research, (i) monitoring and fact finding, (ii) methodological issues, (iii) etiology and causality (the study of mechanisms), and (iv) prevention and intervention.

Monitoring and fact finding. As the psychosocial work environment is changing rapidly, there is a need to adequately monitor psychosocial work conditions and their relations with health and safety. It is important to study trends and changes, also in health risk behavior, and to investigate interrelations between work factors, behavior, and indicators of health and safety. Special groups of workers to be studied include marginalized workers and workers in less developed countries.

Methodological issues. Cross-sectional studies may be adequate for the monitoring of psychosocial work conditions and for studying prevalence, they are ill-suited for studying etiology and causality. They are also not well-suited for studying mediation because of a lack of temporal ordering. If we want to study across-time processes, we need longitudinal designs. This conclusion is echoed in the contributions of this issue of the Scandinavian Journal of Work, Environment \& Health. For example, Åkerstedt (25) explains that longitudinal studies are needed to give us information when acute insomnia becomes more or less chronic and to determine who is susceptible to stress-related sleep impairment. Longitudinal designs are potentially powerful, but we should bear in mind that they, in themselves, are no guarantee for causal inferences.

Some of the authors $(17,27)$ emphasize that researchers should be very critical with regard to their study design. Their message is that the nucleus of scientific research is a strategy called a "plausible rival hypothesis" (ie, a systematic and critical consideration of alternative explanations for the results of a study). These authors and Kivimäki and his colleagues (6) also point out that the study of either naturally occurring or planned change (eg, reorganization, organizational downsizing, change in a shift system or overtime regime) may provide important clues as to causality. [See also the discussion of prevention and intervention that follows.]

Etiology and causality (the study of mechanisms). The study of mechanisms that may explain why and how exposure to certain work characteristics influence health and performance and that may explain how acute reactions, in the long term, turn into more chronic health impairments is intriguing. This is a complicated and multidisciplinary field of research that requires a multimethod and multisource approach. Two central mechanisms stand out, a psychophysiological mechanism and a behavioral lifestyle mechanism. The first mechanism is related to high activation and insufficient recovery and is founded in several theoretical approaches, among them effort-recovery theory and allostatic load theory. It holds that work stress affects health in the long run by direct effects via sustained activation of the autonomic nervous system and enhanced neuroendocrine responses (3). The most interesting in this respect is the study of stress-related sleep quality and quantity. Additional study of psychological and cognitive mechanisms also seems promising. These mechanisms include processes such as rumination, work-related worrying, work anticipation, and the like. The study by Siegrist \& Rödel (3) constitutes important work in the investigation of the second path [ie, the path through (un)healthy behavior]. It can be hypothesized that stress undermines self-control and therefore may, in turn, contribute to unhealthy behavior, both at work (risk taking) 
and in the nonwork area (alcohol, smoking). It can also be hypothesized that not only stressful work characteristics may influence unhealthy life styles, but that the inverse relation is also true. Unhealthy behavior (eg, alcohol consumption), to give one example, may lead to less support from colleagues (reverse causation) or to more risky work behavior. As to these and other mechanisms, much is to be learned in the near future. Recovery and sleep research is a promising avenue for understanding pathways between exposure and illness. Therefore, occupational health and safety research should not only assess the work situation in detail, but also the nonwork situation. For example, as noted by Geurts \& Sonnentag (18), we can study which nonwork activities contribute to or impede the recovery process and attempt to determine through which underlying mechanisms the phenomenon occurs.

Prevention and intervention. Potentially, the intervention study is a strong design, as a well-designed intervention study may provide strong evidence with regard to causality (28). This still is an underdeveloped research field, but no doubt progress is being made. [See the papers by Semmer (27) and Härmä (8).] As in other occupational health and safety areas, the scientific study of interventions to reduce work-related stress is both complicated and challenging. These studies are difficult because the study of interventions in the psychosocial work environment takes place in the quickly changing reality of modern organizations, not in the scientist's controlled laboratory. The major purpose of organizations is not to facilitate highstandard scientific research, involving scientific outsiders and detailed and repeated rounds of data collection. This is no reason for not performing intervention studies in their natural context, however. We need to strive for the best possible quality, bearing in mind that the randomized controlled trial is not the only road to causal evidence. And, as Semmer (27) has made clear, also study designs that are not optimal from a scientists' point of view can provide evidence with respect to causality. An example of an intervention study in a natural context is a study into the effects of longer respites from work, such as vacations, on health and well-being, as suggested by Geurts \& Sonnentag (18).

Studies into work-related stress have taught us a lot about the "bad side of the moon": poorly designed tasks and jobs, poor sleep, unhealthy habits, human errors and accidents, and mental and physical illness. From the same studies, we have also learned that stress and motivation can be regarded as two sides of the same coin. Work stimulates motivation, commitment, performance, and mental health as long as it provides the right "cocktail" of work characteristics [eg, high but not excessively high demands, task variety, much but not too much control (including time control), and support from supervisors and co-workers]. A final suggestion for additional "psychosocial occupational health research" is to broaden this scientific scope, and also "to (always) look at the bright side of (work) life".

\section{References}

1. Kompier MAJ. New systems of work organization and workers' health. Scand J Work Environ Health. 2006;32(6):421430.

2. Kristensen T, Kornitzer M, Alfredsson L. Social factors, work, stress and cardiovascular disease prevention. Brussels: The European Heart Network; 1998.

3. Siegrist J, Rödel A. Work stress and health risk behavior. Scand J Work Environ Health. 2006;32(6):473-481.

4. Karasek RA. Job demands, job decision latitude and mental strain: implications for job redesign. Admin Sci Q. 1979;24:285-307.

5. Siegrist J, Peter R, Junge A, Cremer P, Seidel D. Low status control, high effort at work and ischemic heart disease: prospective evidence from blue-collar men. Soc Sci Med. 1990;31:1127-34.

6. Kivimäki M, Virtanen M, Elovainio M, Kouvonen A, Väänänen A, Vahtera J. Work stress in the etiology of coronary heart disease-a meta-analysis. Scand J Work Environ Health. 2006;32(6):431-442.

7. Stansfeld S, Candy B. Psychosocial work environment and mental health-a meta-analytic review. Scand J Work Environ Health. 2006;32(6):443-462.

8. Härmä M. Workhours in relation to work stress, recovery and health. Scand J Work Environ Health. 2006;32(6):502-514.

9. Vahtera J, Kivimäki M, Pentti J, Linna A, Virtanen M, Virtanen P, et al. Organisational downsizing, sickness absence, and mortality: 10-town prospective cohort study. BMJ. 2004;328:555.

10. Vahtera J, Kivimäki M, Forma P, Wikström J, Halmeenmäki T, Linna A, et al. Organizational downsizing as a predictor of 
disability pension: the 10-Town prospective cohort study. J Epidemiol Community Health. 2005;59:238-42.

11. Westerlund H, Ferrie J, Hagberg J, Jeding K, Oxenstierna G, Theorell T. Workplace expansion, long-term sickness absence, and hospital admission. Lancet. 2004; 363:1193-7.

12. Kivimäki M, Vahtera J, Pentti J, Ferrie JE. Factors underlying the effect of organisational downsizing on health of employees: longitudinal cohort study. BMJ. 2000;320:971-5.

13. Van der Hulst M. Long workhours and health. Scand J Work Environ Health. 2003;29:171-88.

14. Ala-Mursula L, Vahtera J, Pentti J, Kivimäki M. Effect of employee worktime control on health: a prospective cohort study. Occup Environ Med. 2004;61:254-61.

15. Ala-Mursula L, Vahtera J, Linna A, Pentti J, Kivimäki M. Employee worktime control moderates the effects of job strain and effort-reward imbalance on sickness absence: the 10-Town study. J Epidemiol Community Health. 2005;59:851-7.

16. Ala-Mursula L, Vahtera J, Kouvonen A, Väänänen A, Linna A, Pentti J, et al. Long hours in paid and domestic work and subsequent sickness absence: does control over daily hours matter? Occup Environ Med. 2006;63:608-16

17. Taris TW, Kompier MAJ. Game researchers play-extreme-groups analysis and mediation analysis in longitudinal occupational health research. Scand J Work Environ Health. 2006;32(6):463-472.

18. Geurts SAE, Sonnentag S. Recovery as an explanatory mechanism in the relation between acute stress reactions and chronic health impairment. Scand J Work Environ Health. 2006;32(6):482-492.

19. Kalimo R, Tenkanen L, Härmä M, Poppius E, Heinsalmi P. Job stress and sleep disorders: findings from the Helsinki Heart Study. Stress Med. 2000;16:65-75.

20. Åkerstedt T, Knutsson A, Westerholm P, Theorell T, Alfredsson L, Kecklund G. Sleep disturbances, work stress and work hours: a cross-sectional study. J Psychosom Res. 2002;53:741-8.

21. Ayas N, White D, Manson J, Stampfer M, Speizer F, Malhotra A, et al. A prospective study of sleep duration and coronary heart disease in women. Arch Intern Med. 2003;163:205-9.

22. Eaker ED, Pinsky J, Castelli WP. Myocardial infarction and coronary death among women: psychosocial predictors from a 20-year follow-up of women in the Framingham study. Am J Epidemiol. 1992;135:854-64.

23. Meisinger C, Heier M, Loewel H. Sleep disturbance as a predictor of type 2 diabetes mellitus in men and women from the general population. Diabetelogia. 2005;48:235-41.

24. Nilsson P, Rööst M, Engström G, Hedblad B, Berglund G. Incidence of diabetes in middle-aged men is related to sleep disturbances. Diabetes Care. 2004;27:2464-9.

25. Åkerstedt T. Psychosocial stress and impaired sleep. Scand J Work Environ Health. 2006;32(6):493-501.

26. McEwen BS. Protective and damaging effects of stress mediators. N Eng J Med. 1998;338:171-9.

27. Semmer NK. Job stress interventions and the organization of work. Scand J Work Environ Health. 2006;32(6):515-527.

28. Kristensen T. Workplace intervention studies. Occup Med. 2000;15(1)293-305.

\section{Mikko Härmä, MD}

Centre of Expertise on Human Factors at Work

Finnish Institute of Occupational Health

Helsinki, Finland

Jussi Vahtera, MD

Unit of Excellence in Psychosocial Factors

Finnish Institute of Occupational Health

Helsinki, Finland
Michiel AJ Kompier, PhD

Department of Work and Organizational Psychology

Radboud University Nijmegen

Nijmegen, Netherlands 
